\title{
Study of the Structural and Mechanical Properties of Recycled High Density Polyethylene/Palm Kernel Shell Ash Bio-Composite
}

\author{
$\begin{array}{lll}\text { C. J. Agbo } & 1^{*} & \text { B.A. Okorie } \\ & \text { H. K. Idu }\end{array}$ \\ 1.Department of Metallurgical and Materials Engineering, \\ Enugu State University of Science and Technology, Enugu, Nigeria \\ 2.Department of Industrial Physics, Ebonyi State University, Abakaliki, Nigeria
}

\begin{abstract}
This study examined the structure and mechanical properties of recycled high density polyethylene(RHDPE)/palm kernel shell ash (PKSA) bio-composite. The reinforcement was added to the polymer matrix in concentrations of $5,10,15,20$ and $25 \mathrm{wt} \%$ and particle sizes of $100,150,200,250,300 \mu \mathrm{m}$. The composite samples were produced using injection moulding technique and subjected to mechanical and tribological property tests for percentage elongation, ultimate tensile strength, and hardness. The structure of the composite samples was analyzed using an optical metallurgical microscope. Results of the structural analysis revealed that the reinforcement of small particle size $(100 \mu \mathrm{m})$ formed a better interfacial bond with the polymer matrix compared with that of other particles sizes. The structural analysis also revealed uniform distribution of hard and brittle particles of the reinforcement in the polymer matrix. Mechanical test results showed that addition of palm kernel shell ash to the polymer matrix decreased its percentage elongation and impact strength by $24.5 \%$ and $22 \%$ respectively but significantly increased the tensile strength and hardness by $107.9 \%$ and $72 \%$ respectively. The ultimate tensile strength, and hardness of the developed composite increased with decrease in reinforcement particle size. Maximum ultimate tensile strength of $131 \mathrm{MPa}$ was obtained by the RHDP containing $10 \mathrm{wt} \%$ PKSA of $100 \mu \mathrm{m}$ particle size while maximum hardness value of $86 \mathrm{BHN}$ was obtained at $25 \mathrm{wt} \%$ palm kernel shell ash of $100 \mu \mathrm{m}$ particle size addition. Palm kernel shell ash reinforced recycled high density polyethylene bio-composite of improved mechanical properties that can be applied in production of engineering components.
\end{abstract}

Keywords: Palm kernel shell ash, RHDPE, Percentage elongation, Ultimate tensile strength, Hardness.

DOI: $10.7176 / \mathrm{CPER} / 62-05$

Publication date: January $31^{\text {st }} 2020$

\section{Introduction}

The demand for agricultural waste materials as a promising replacement of high density, very costly and environmental hazardous organic reinforcement for composite materials has increased significantly (Vishnu et al., 2014). These natural available wastes have good promising properties such as good strength, light in weight, cost effective and free of hazardous chemicals during use. Research has proven the reliability of natural waste materials as good replacement of glass fiber for polymer reinforcement (Mohanty et al, 2002). The emergence of agricultural waste materials will help in curbing the dangerous menace of environmental pollution posed by the use of synthetic materials or glass as reinforcement in composite production (Sarki et al., 2011). From the previous studies, composites material reinforced with natural fibers has been identified with good resistance to chemical attack, better acoustic insulation; good thermal and electrical properties.

Composite constitutes discrete constituents intimately bonded together to achieve a new property usually the combination of the properties of the individual constituents (Surappa and Rohatgi, 1981). The most important motivation for composites development is that it embodied the individual characteristics of the constituents bonded together (Surappa and Rohatgi, 1981). Composite characteristics are dependent on the inherent properties of the individual materials, dispersion and the orientation of the reinforcing particulates in the matrix. Composites properties can also be dependent on the wettability or the adhesion of the reinforcement to the matrix.

Study by Rafiullah and Akhtar, (2014) showed that the emergence of composite materials was as a result of recent advancement of technology which led to increase in demand of materials with specific unique properties. These also contributed significantly to the recent demand of composite in various industries including automotive, aerospace, and sports industries (Miracle, 2005).

In composite production, the matrix serves as the solvent while the reinforcement serves as the solute. The reinforcement could be applied as particulates, fibres of different orientations, or as sheet. The matrix could be a ceramic material, metal, alloy or polymer material. The "hard" reinforcement is distributed in a continuous phase (the matrix) and the matrix forms a percolating network; therefore embedded with the reinforcements to form a new material (Swammy et al., 2011). The reinforcements are quite stronger than the matrix, hence basically bonded to the matrix to enhance its strength, hardness and wear properties. The reinforcements are not soluble to the matrix, so are laid side by side with the matrix. Hence the need to increases the wettability of the reinforcement to the matrix for effective bonding and improved properties. In this study, the major aim is to investigate the structure and mechanical properties of palm kernel shell ash (PKSA) reinforced recycled high density polyethylene 
bio-composite. In the literature, the viability of exploiting palm kernel shell ash (PKSA) is rarely reported, hence this research forms a fundamental step towards further research in establishing the optimised conditions needed for maximal utilization of this natural resource.

\section{Materials and method \\ Materials}

Palm kernel shell ash and recycled high density polyethylene were adopted as the base materials for this research. Palm kernel shell ash served as the reinforcement while recycled high densitypolyethylene served as the polymer matrix. Equipment used for this research were industrial sieves, injection moulding machine, electronic compact scale (Model: BL20001), hack saw, vice, optical microscope (Model: L2003A), digital camera, Brinell hardness tester (Model: DHT-6), and 100kN capacity tensometer (Model: 130812).

\section{Materials Sourcing and Preparation}

The recycled high densitypolyethylene was procured from Demolinks Enterprise Nigeria Limited, Awada Onitsha, Anambra State, Nigeria while the palm kernel shell was sourced locally. The recycled high density polyethylene was obtained in pellet form while the palm kernel shell after been dried was burnt, ground into powder and sieved into particle sizes of $100,150,200,250$ and $300 \mu \mathrm{m}$ accordance to BS1377:1990 standard.

\section{Composite Production}

The composites were produced with the varying ratios of polymer matrix to palm kernel shell ash reinforcement. The reinforcement was added in concentrations of 5, 10, 15, 20 and $25 \mathrm{wt} \%$ at particle sizes of 100, 150, 200, 250 and $300 \mu \mathrm{m}$. The injection molding machine was heated to $220^{\circ} \mathrm{C}$. Thereafter the palm kernel shell ash/recycled high density polyethylene in the designed ratios were poured into the Auger of an injection molding machine. The melt was then injected into the molding chamber where it was steam cooled.

\section{Mechanical Properties Test of the Developed composite \\ Tensile Strength Test}

The strength of the developed samples was determined using $100 \mathrm{kN}$ capacity tensometer (Model: 130812) at Cutix Cable Plc, Nnewi, Anambra State, Nigeria. The test sample was clamped at the jaws of the tensile strength tester. A tensile load of $100 \mathrm{kN}$ was applied to the specimen until the test specimen fractured. The tensile load and extension at the point of fracture were read and recorded, after which the UTS and ductility were calculated using equations 1 and 2 .

Ultimate tensile strength $(\mathrm{UTS})=\frac{\text { Maximum Force }(\mathrm{N})}{\text { Original C.S.A }\left(\mathrm{mm}^{2}\right)}=\frac{\mathrm{P}_{\max }}{\mathrm{A}}$

$\%$ Elongation $=\frac{\text { Final guage length }- \text { Original guage length }}{\text { Original gauge length }} \times 100$

\section{Hardness test}

The Brinell hardness test was conducted to determining the resistance of the developed composites to indentation. This was done using Brinell hardness tester (Model: DHT-6) at Delta State Polytechnic, Ogwashi-uku. The specimen was placed on an Equotip test block and the machine was operated automatically until the indenter touched the surface of the specimen. The value was read directly from the machine's scale and the result was recorded.

\section{Results and discussion}

Mechanical properties of palm kernel shell ash reinforced recycled high density polyethylene bio-composite. The percentage elongation $(\% \mathrm{E})$ and ultimate tensile strength (UTS) of recycled high density polyethylene (RHDPE)/palm kernel shell ash bio-composite are presented in Figures 1 to 4.

Figures 1 and 2 show the effect of palm kernel shell ash content and particle size on the percentage elongation of reinforced recycled high density polyethylene bio-composite. Figure 4.1 reveals $24.5 \%$ decrease in percentage elongation of the recycled polyethylene by addition of $5 \mathrm{wt} \%$ palm kernel shell ash of $100 \mu \mathrm{m}$ particle size. Figure 2 shows that the percentage elongation of the developed bio-composite decreased with increase in palm kernel shell ash particle size. Figure 2 shows that sample containing $25 \mathrm{wt} \%$ palm kernel shell ash of $300 \mu \mathrm{m}$ particle size showed the least percentage elongation. This could be as a result of increased dispersion and amount of PKSA particles in the polymer matrix. These particulates are very hard and brittle (Danladi and Shu'aib, 2014; Oladele et al., 2014). 


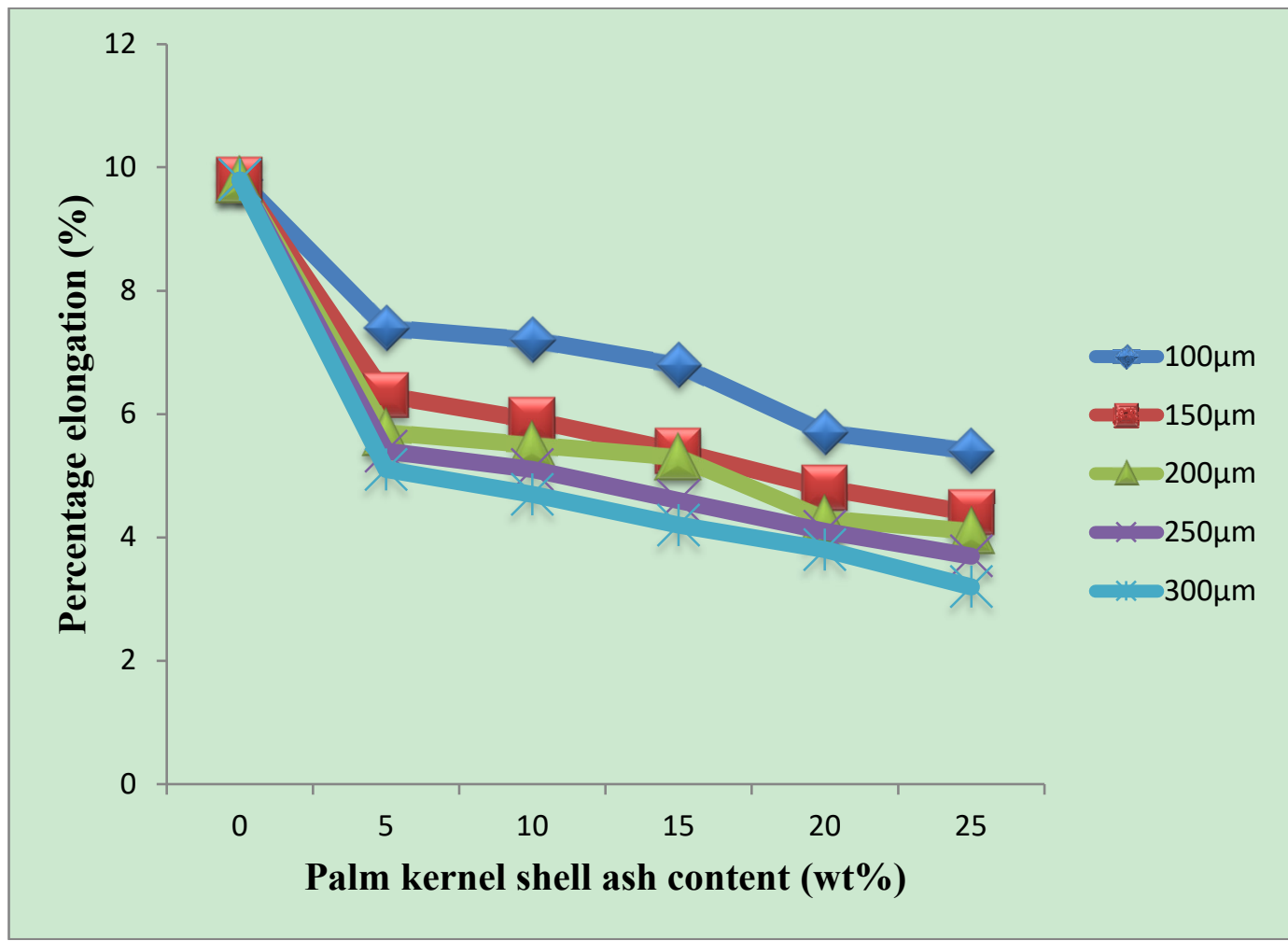

Figure 1: Effect of PKSA content on the percentage elongation of palm kernel shell ash reinforced recycled high density polyethylene bio-composite

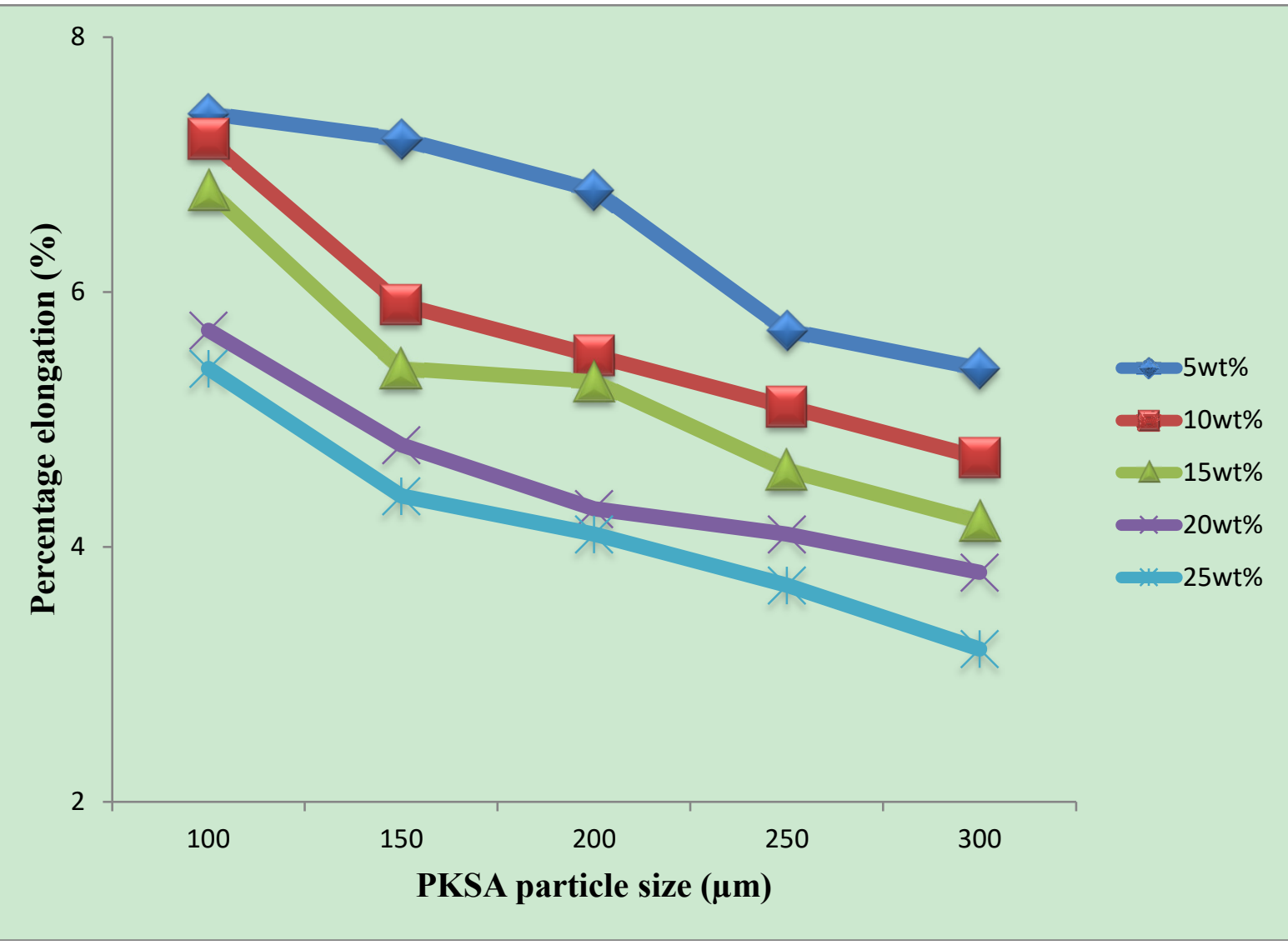

Figure 2: Effect of PKSA particle size on the percentage elongation of reinforced recycled high density polyethylene bio-composite 
Figures 3 and 4 indicate the variation of UTS of recycled high density polyethylene matrix with PKSA content and particle size respectively. Figure 3 shows a substantial improvement in ultimate tensile strength (107.9\% increase) of the reinforced recycled high density polyethylene when compared with the unreinforced polymer matrix at $10 \mathrm{wt} \%$ PKSA of $100 \mu \mathrm{m}$ particle size. Figure 3 shows that the UTS of the reinforced polymer matrix increased as the concentration of the reinforcement increased to $10 \mathrm{wt} \%$ and decreased with further increase in reinforcement content. This could be as a result of increasing content of PKSA in the polymer matrix and weak bonding effect of the reinforcement to the polymer matrix (Raghvendra et al., 2008; Manoj et al., 2013). Figure 4 indicates that the UTS of the developed bio-composite decreased with increasing reinforcement particle size. Maximum ultimate tensile strength of $131 \mathrm{MPa}$ was obtained by the sample containing $10 \mathrm{wt} \%$ reinforcement of $100 \mu \mathrm{m}$ particle size.

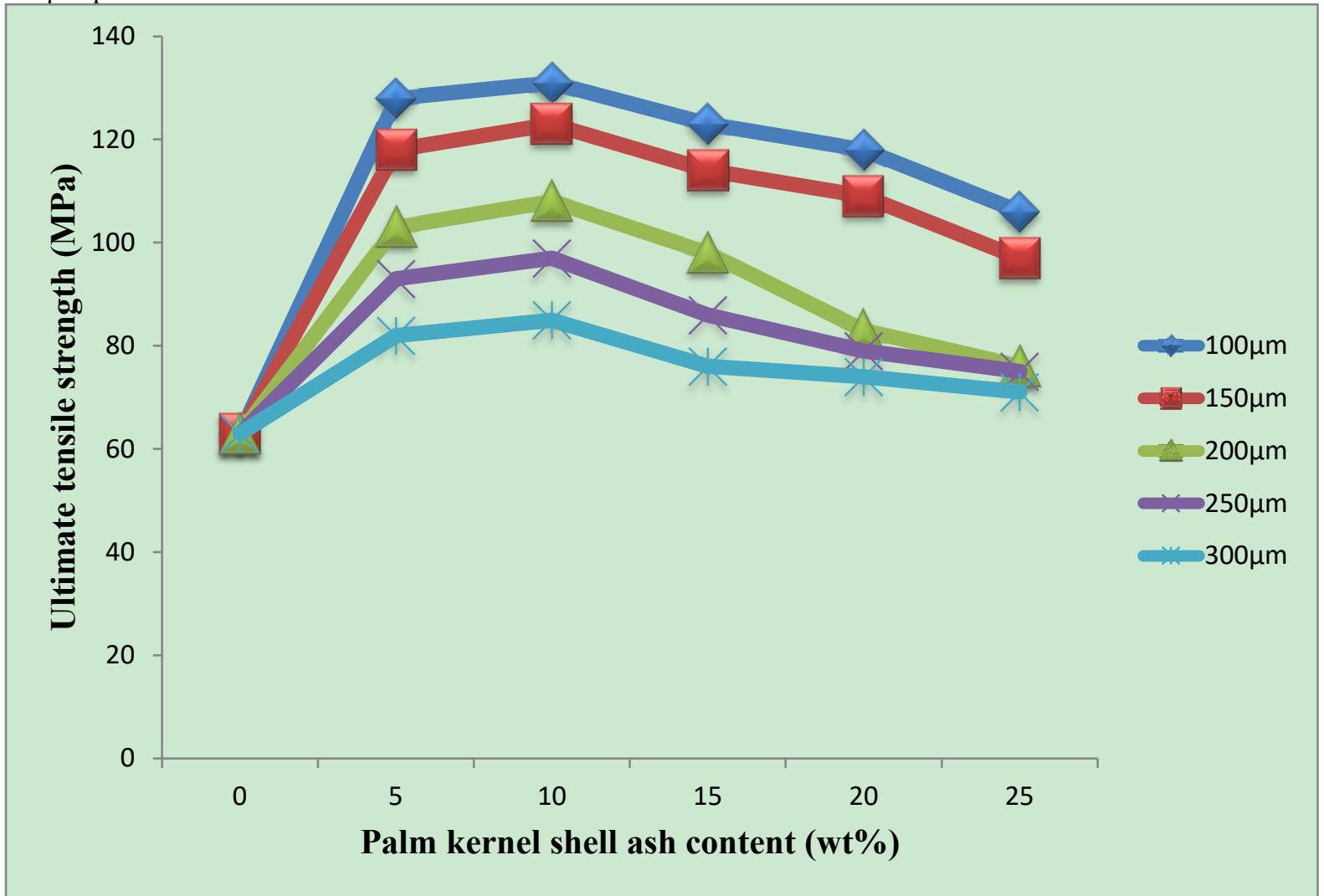

Figure 3: Effect of PKSA content on the ultimate tensile strength of palm kernel shell ash reinforced recycled high density polyethylene bio-composite. 


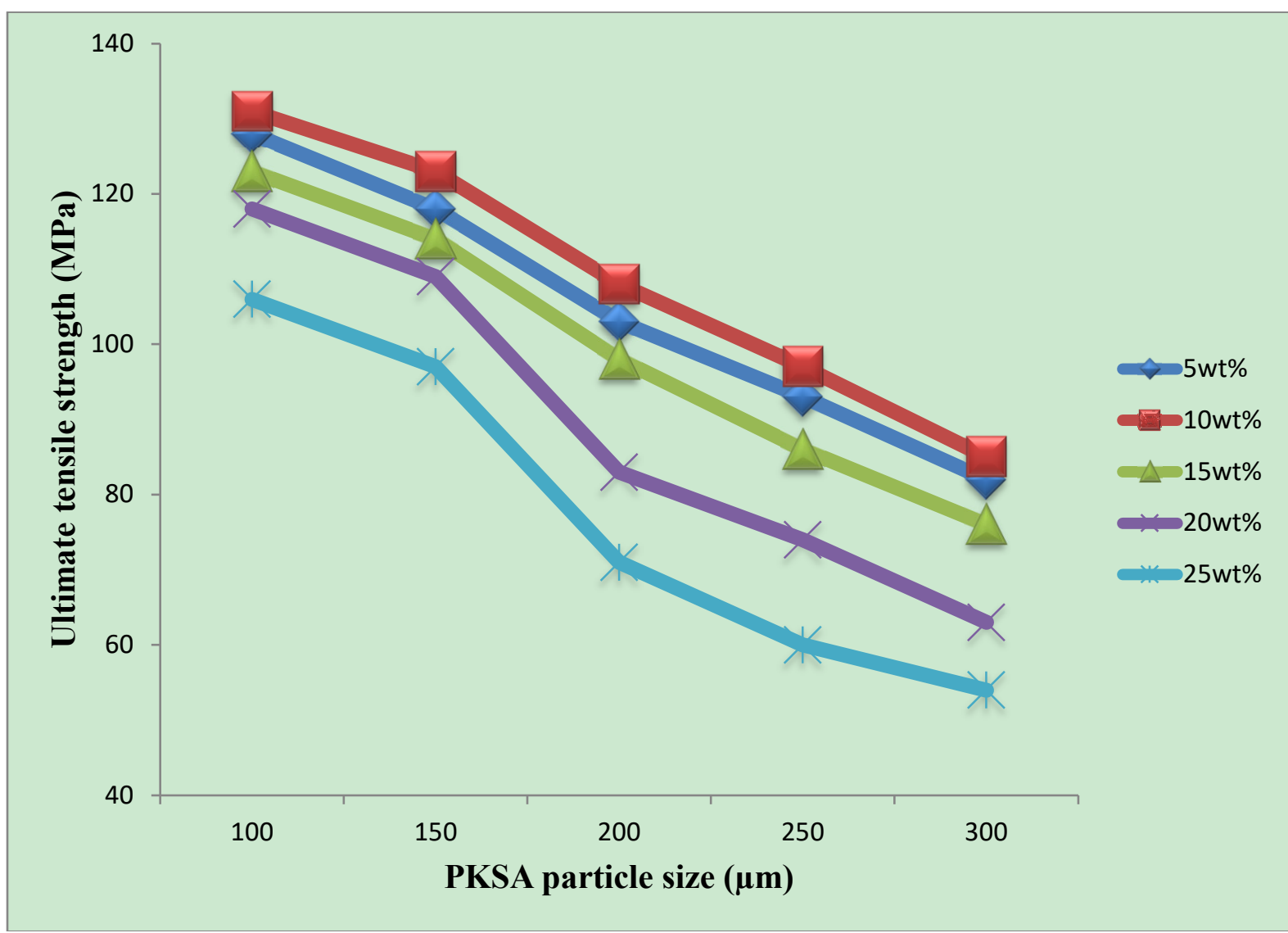

Figure 4: Effect PKSA particle size on the ultimate tensile strength of reinforced recycled high density polyethylene bio-composite.

Figures 5 and 6 depict the variation of Brinell hardness of palm recycled high density polyethylene matrix with kernel shell ash content and particle size respectively. It can be seen in Figure 5 that addition of $5 \mathrm{wt} \%$ palm kernel shell ash of $100 \mu \mathrm{m}$ particle size to polymer matrix substantially increased the hardness of the developed composite by $36 \%$ increase. Figure 6 also shows that hardness of the reinforced polymer matrix decreased with increase in palm kernel shell ash particle size. Samples containing palm kernel shell ash of small particle size $(100 \mu)$ shows better hardness property than the samples containing reinforcement of large particle size $(300 \mu \mathrm{m})$. This could be linked to effective wettability of PKSA to the polymer matrix (Abdel -Salam et al., 2011). The hardness of the developed composite increased correspondingly with increasing palm kernel shell ash content with maximum hardness value of $86 \mathrm{BHN}$ obtained by the sample containing $25 \mathrm{wt} \%$ palm kernel shell ash of $100 \mu \mathrm{m}$ particle size (Fig. 6). 


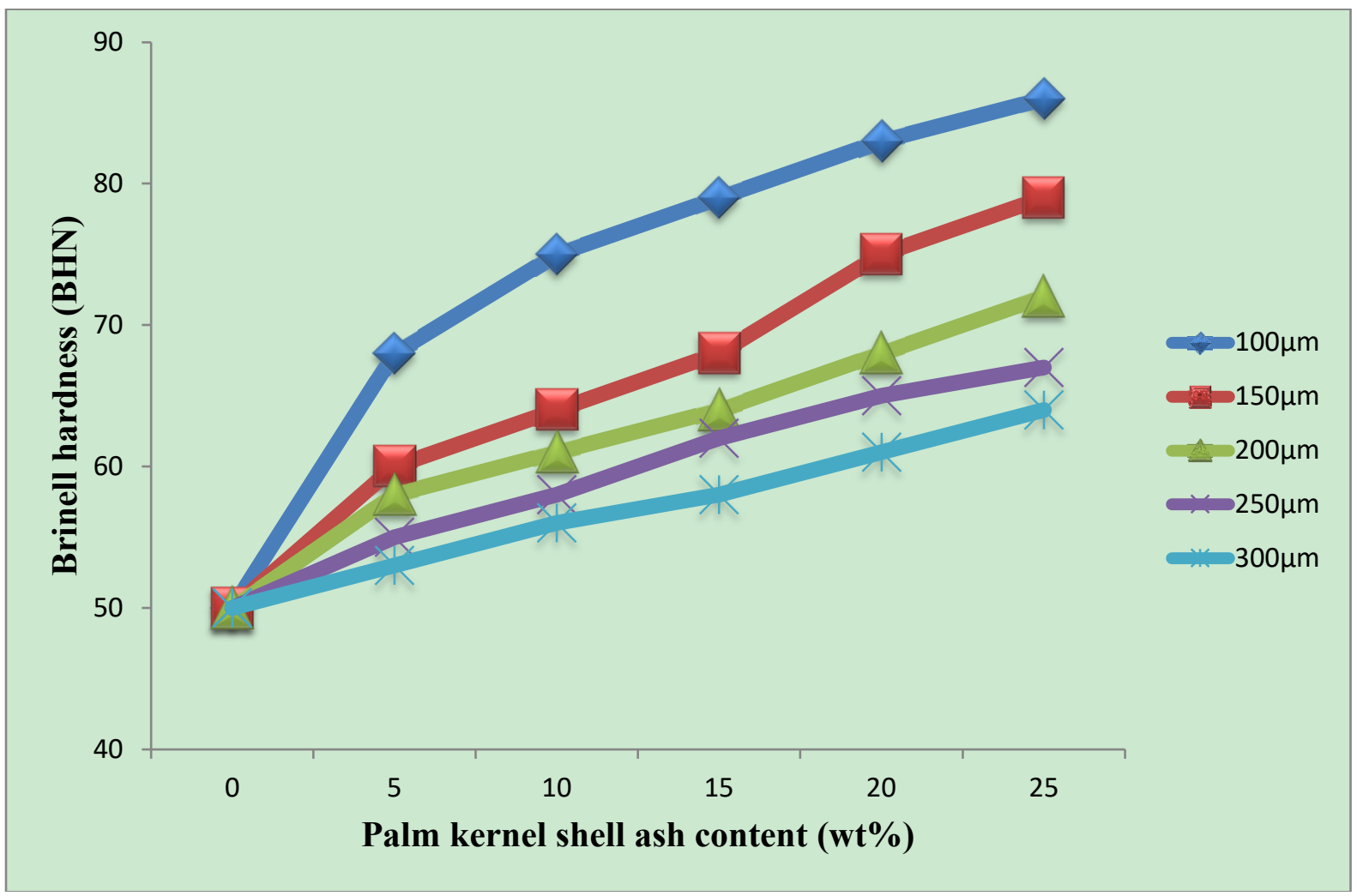

Figure 5: Effect of PKSA content on the hardness of palm kernel shell ash reinforced recycled high density polyethylene bio-composite.

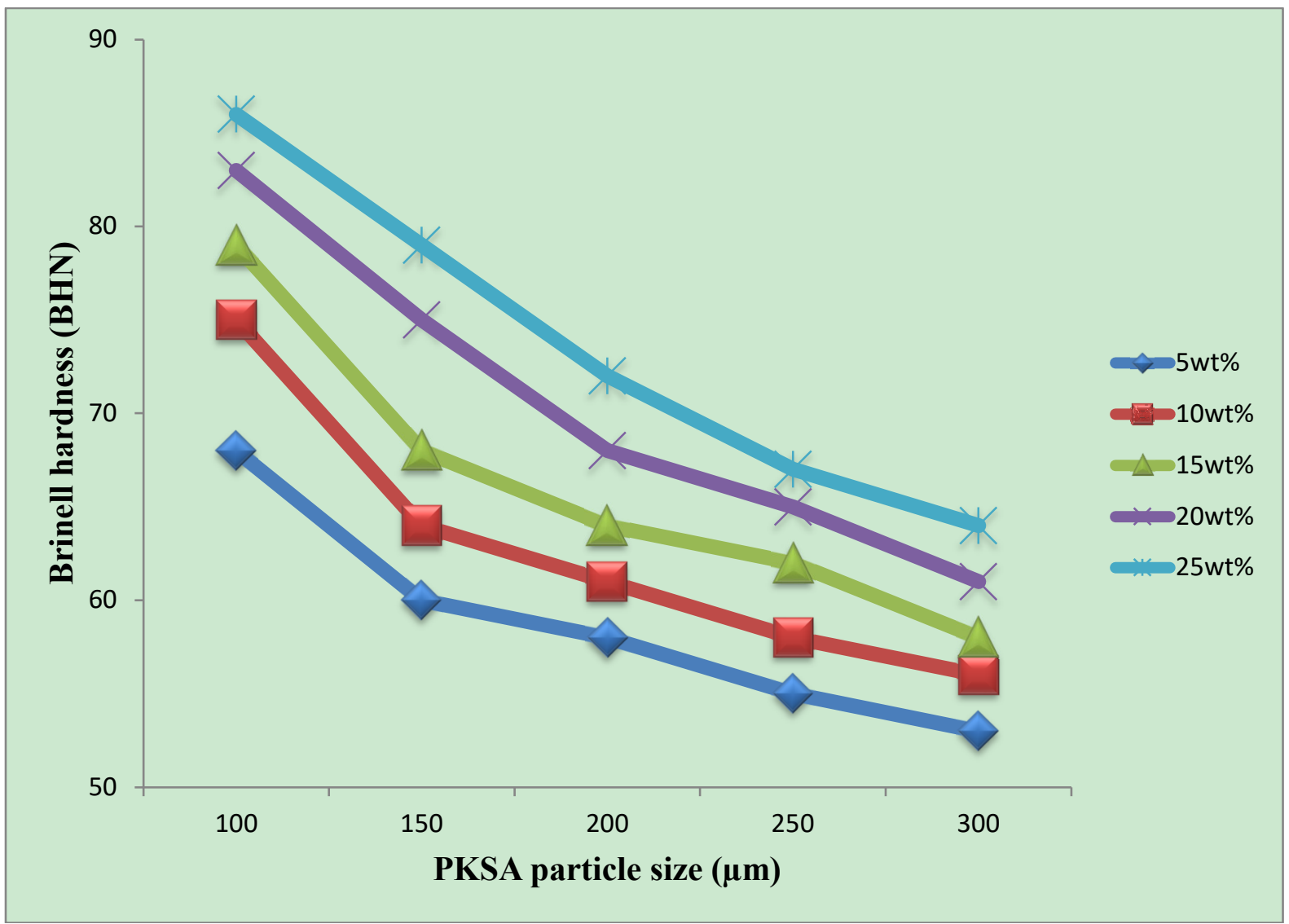

Figure 6: Effect of PKSA particle size on the hardness of reinforced recycled high density polyethylene bio-composite. 
Optical microscopy analysis of the developed composite

Figures 7-10 show the micrographs of recycled high density polyethylene (RPE) matrix reinforced with different concentration of palm kernel shell ash (PKSA) of particle size of $100 \mu \mathrm{m}$. Figs. 7-10 reveal effective dispersion of the perm kernel shell ash in the recycled high density polyethylene matrix which systematically led to substantial improvement of the ultimate tensile strength and hardness of the developed composite as shown in Figures 7-9. It can also be seen in Figs.7-10 that increasing palm kernel shell ash content increased the carbon content in the polymer matrix which could be linked to the increased hardness and decreased UTS of the composite.

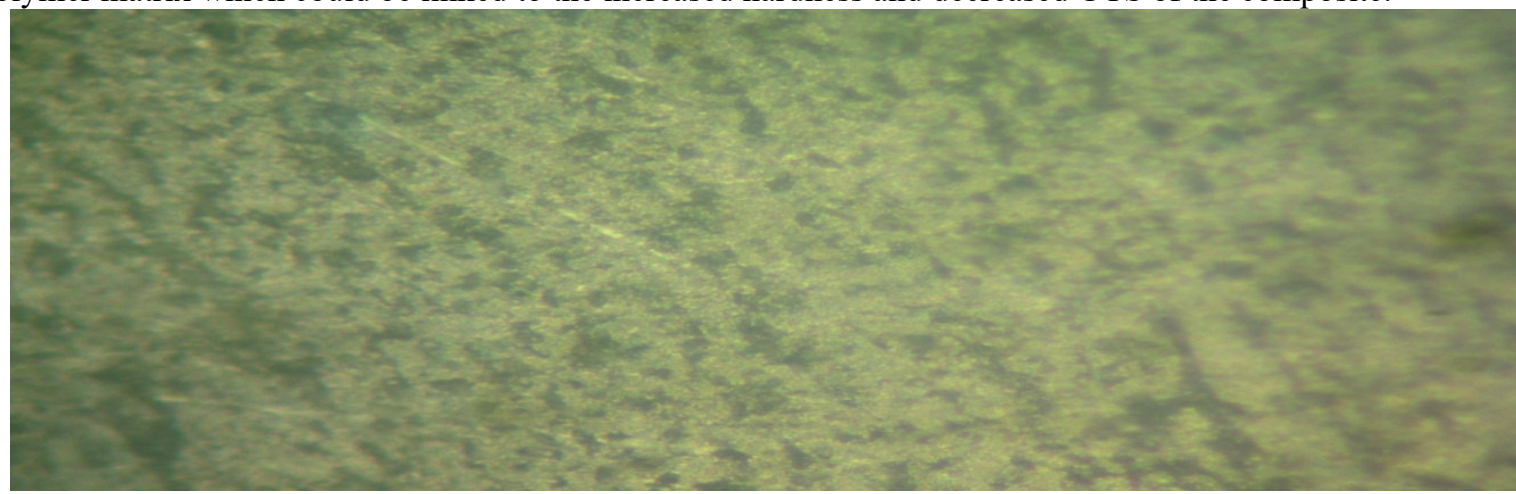

Figure 7: Micrograph of RPE matrix reinforced with 5wt\%PKSA of $100 \mu \mathrm{m}$ particle size

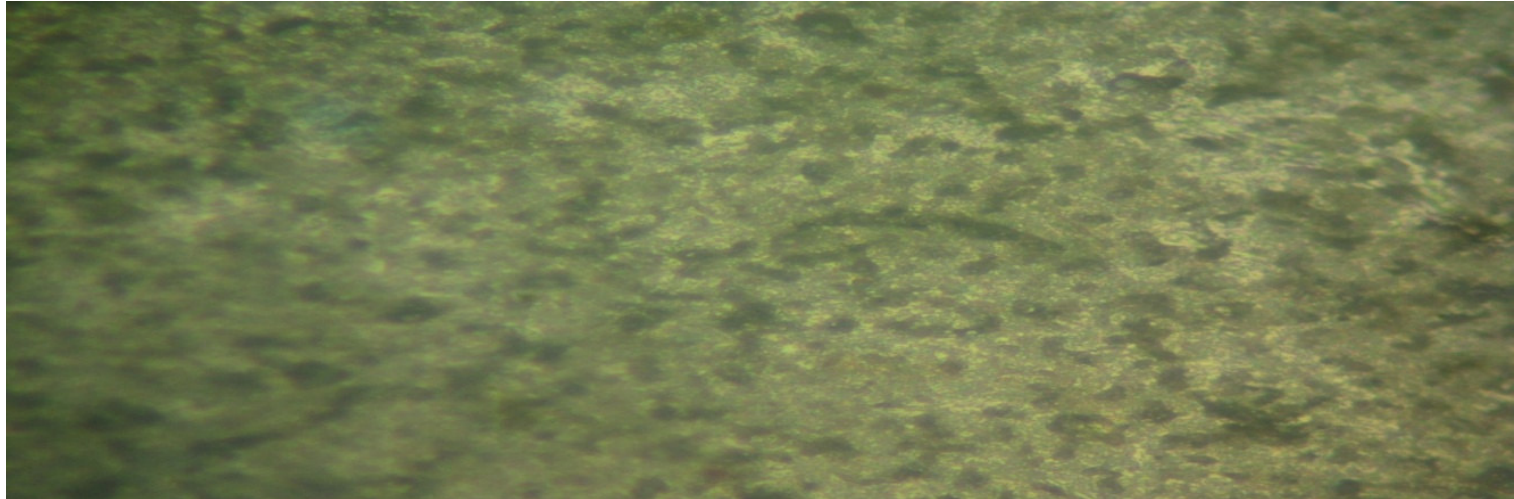

Figures 8: Micrograph of RPE matrix reinforced with 10wt\%PKSA of $100 \mu \mathrm{m}$ particle size

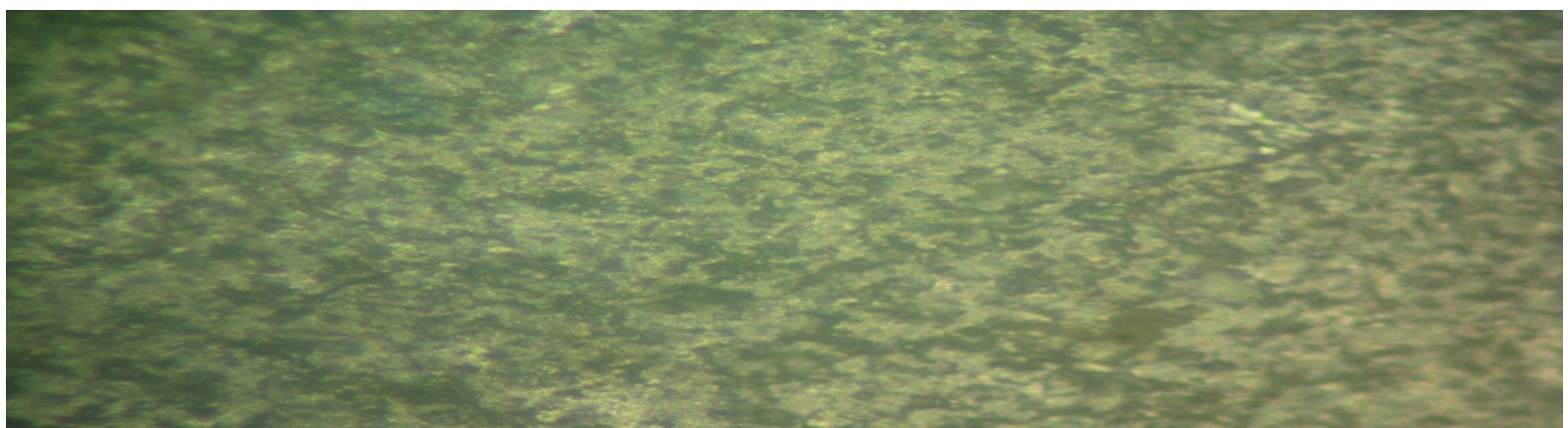

Figure 9: Micrograph of RPE matrix reinforced with 20wt\%PKSA of $100 \mu \mathrm{m}$ particle size 


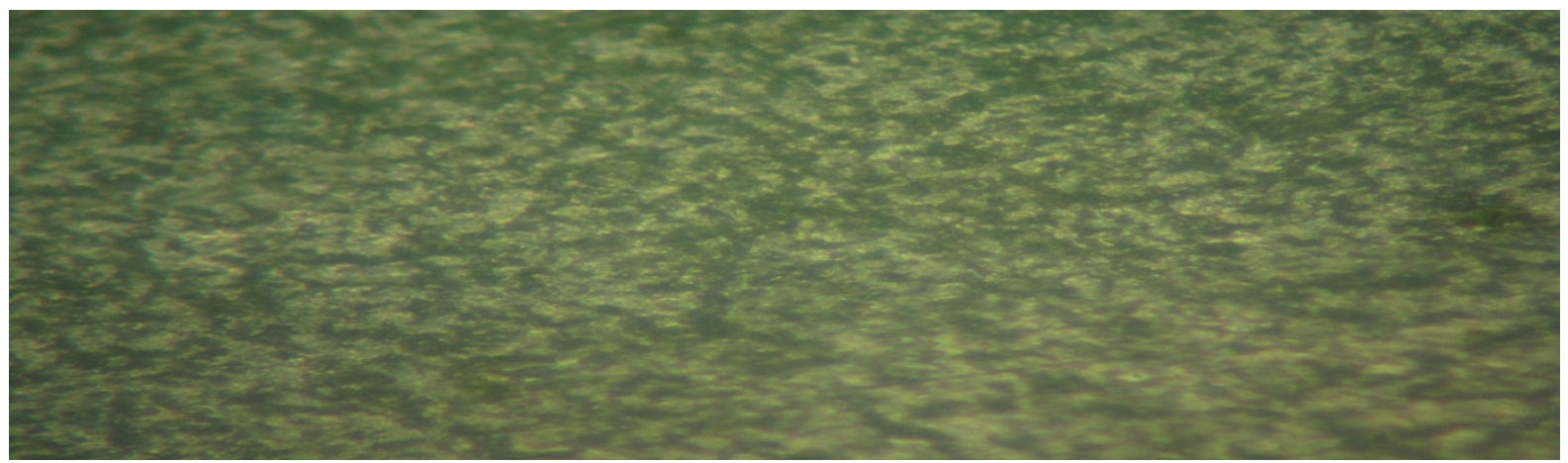

Figure 10: Micrograph of RPE matrix reinforced with 25wt\%PKSA of $100 \mu \mathrm{m}$ particle size

\section{Conclusion}

This research investigated the structure and mechanical properties of palm kernel shell ash reinforced recycled high density polyethylene matrix bio-composite. The following conclusions were drawn:

i. Addition of $5 \mathrm{wt} \%$ of palm kernel shell ash to the recycled high density polyethylene decreased the ductility and impact strength of the recycled high density polyethylene matrix by $24.5 \%$ and $22 \%$ respectively at $5 \mathrm{wt} \%$ addition and $100 \mu \mathrm{m}$ particle size.

ii. The percentage elongation and impact strength of the developed bio-composite decreased with increasing palm kernel shell ash particle size.

iii. Sample containing $25 \mathrm{wt} \%$ palm kernel shell ash of $300 \mu \mathrm{m}$ particle size showed the least percentage elongation resulting from the increased carbon content from PKSA in the polymer matrix.

iv. Addition of palm kernel shell ash to recycled high density polyethylene significantly increased the UTS and Brinell hardness of the reinforced polymer matrix by $107.9 \%$ and $72 \%$ respectively at $25 \mathrm{wt} \%$ PKSA of $100 \mu \mathrm{m}$ particle size.

v. The ultimate tensile strength of the developed bio-composite decreased with increasing PKSA particle size.

vi. The ultimate tensile strength of the reinforced polymer matrix increased as the concentration of the reinforcement increased to $10 \mathrm{wt} \%$ and decreased with further increase in reinforcement volume. This could be as a result of weak interfacial bonding of the reinforcement with the polymer matrix.

\section{References}

Abdel -Salam S., Metwally M. S., Abdel- Hakim A. A., El B. S. and Elshafie E. S. (2011) Effect of mineral fillers on rice straw fiber/high density polyethylene composites. Nature and Science, 9(12):116-124.

Chinomso M. E. and Isaac O. I. (2012) Properties of oil palm empty fruit bunch fibre filled high density polyethylene. International Journal of Engineering and Technology, 3 (6): 458-471.

Danladi A. and Shu'aib J. (2014) Fabrication and properties of pineapple fibre/high density polyethylene composites. American Journal of Materials Science, 4(3): 139-143.

Manoj K., Rakesh K. S., Shekhar H. and Poomalai P. (2013) Studies on banana fiber reinforced high density polyethylene (HDPE)/polyamide (PA)-66 blend composites. Wudpecker Journal of Food Technology, 1(4): $062-073$.

Miracle D. B. (2005) Metal matrix composites - from science to technological significance. Composite Science Technology, 65(25): 26-40.

Mohanty AK, Misra M, Drzal LT. Sustainable bio-composites from renewable resources: opportunity and challenges in the green materials world. J Polym Environ, 10(1): 19-26.

Mwaikambo, L. Y. and Ansell M. P. (2006). Mechanical properties of alkali treated plant fibers and their potential as reinforcement materials i. hemp fibre. J. Materials Science, 41, $2483-2496$.

Oladele I. O., Omotoyimbo J. A. and Ayemidejor S. H. (2014)Mechanical Properties of chicken feather and cow hair fiber reinforced high density polyethylene composites. International Journal of Science and Technology, 3(1): 66-71.

Rafiullah A. and Akhtar H. A. (2014) Mechanical properties of aluminium matrix nano-composite reinforced with silicon carbide.International Journal of Science and Research (IJSR). 3(9): 703-706.

Raghvendra K. M., Sandeep K., Kumar S. and Ashok M. (2008) Dynamic analysis of banana fiber reinforced highdensity polyethylene/poly (-caprolactone) composites. Journal of Mechanics of Materials and Structures, 3(1): 107-125.

Sarki, J., Hassana, S.B., Aigbodiona, V.S. and J.E. Oghenevwetaa, (2011) Potential of using coconut shell particle fillers in eco-composite materials. Journal of Alloys and Compounds 509, 2381-2385.

Surappa M. K. and Rohatgi P. K. (1981) Preparation and properties of aluminium alloy ceramic particle composites. J. Mater. Sci. 16: 983-993. 
Swamy A. R. K., A. Ramesha, G.B. Veeresh Kumar, and J. N. Prakash (2011) Effect of particulate reinforcements on the mechanical properties of Al6061-WC and A16061-Gr MMCs. Journal of Minerals and Materials Characterization and Engineering, 10(12): 1141-1152.

Wannik W. B., Ayob A. F., Syahrullail S., Masjuki H. H. and Ahmad M. F. (2012) The effect of boron friction modifier on the performance of brake pads.International Journal of Mechanical and Materials Engineering 7 (1): 31- 35.

Xiaran M., Yuanjiang Q., Xiaoyun L., Yuzhu W., Xiaolong L., Feng T., Hui L., Fenggang B., Jie W. and Xiuhong L. (2013) Role of multiwalled carbon nanotube on mechanical reinforcement of high-density polyethylene. Advanced Materials Research. 652 (654): 15-24.

Vishnu P., Ajil J., Venkatachalama G., Narayanana S. and S. Rajakumarb (2014). Finite element analysis of jute and banana fibre reinforced hybrid polymer matrix composite and optimization of design parameters using ANOVA technique. Procedia Engineering 97, 1116 - 1125.

Zamri Y.B., Shamsul J. B. and Amin M. M. (2011). Potential of palm oil clinker as reinforcement in aluminium matrix composites for tribological applications.International Journal of Mechanical and Materials Engineering 6 (1): 10-17. 